\title{
Benzodiazepine administration during adult cardiac surgery: a survey of current practice among Canadian anesthesiologists working in academic centres
}

\section{L'administration de benzodiazépines pendant la chirurgie cardiaque chez l'adulte: évaluation de la pratique actuelle des anesthésiologistes canadiens exerçant en milieu universitaire}

\author{
Jessica Spence, MD (D) - Emilie Belley-Côté, MD, FRCPC · P. J. Devereaux, MD, PhD, FRCPC • \\ Richard Whitlock, MD, PhD, FRCPC · Kevin Um, BA · Graham McClure, BSc • \\ Andre Lamy, MD, MHSc, FRCPC • Yannick LeManach, MD, PhD • \\ Stuart Connolly, MD, FRCPC $\cdot$ Summer Syed, MD, MSc, FRCPC
}

Received: 7 October 2017/Revised: 25 November 2017 / Accepted: 27 November 2017/Published online: 18 December 2017 (C) Canadian Anesthesiologists' Society 2017

\begin{abstract}
Background Benzodiazepines are commonly administered during cardiac surgery because of their limited effect on hemodynamics and presumed role in preventing intraoperative awareness. Recent concerns about an increased risk of delirium with benzodiazepines have resulted in decreased usage in the intensive care unit and in geriatric perioperative practice. Little is known, however, about current benzodiazepine usage in the setting of adult cardiac surgery.

Methods We contacted all academic anesthesia departments in Canada to identify practicing attending cardiac anesthesiologists; this group constituted our
\end{abstract}

Electronic supplementary material The online version of this article (https://doi.org/10.1007/s12630-017-1047-1) contains supplementary material, which is available to authorized users.

J. Spence, MD $(\varangle) \cdot$ Y. LeManach, MD, PhD

Departments of Anesthesia and Critical Care and Health

Research Methods, Evidence, and Impact, McMaster University,

Population Health Research Institute (PHRI), 2V9-1280 Main St.

West, Hamilton, ON L8S 4K1, Canada

e-mail: jessicaspence13@gmail.com

E. Belley-Côté, MD, FRCPC

Departments of Anesthesia and Critical Care, Medicine (Cardiology) and Health Research Methods, Evidence, and Impact, McMaster University, Population Health Research Institute, Hamilton, ON, Canada

P. J. Devereaux, MD, PhD, FRCPC

Departments of Medicine (Cardiology) and Health Research

Methods, Evidence, and Impact, McMaster University,

Population Health Research Institute, Hamilton, ON, Canada sampling frame. Information regarding participant demographics, benzodiazepine usage, type, dose, and other administration details were obtained by electronic survey. Responses were analyzed descriptively.

Results The survey was completed by 243/346 (70\%) of cardiac anesthesiologists. Eleven percent of respondents do not administer benzodiazepines. Midazolam was the most commonly used benzodiazepine, with a mean (standard deviation) dose of 4.9 (3.8) $\mathrm{mg}$ given to an average patient. When respondents were asked the proportion of patients that they gave benzodiazepines, the response was bimodal. The most common considerations that influenced benzodiazepine use were patient age (73\%), patient anxiety (63\%), history of alcohol/drug/ benzodiazepine use (60\%), and the presence of risk factors for intraoperative awareness (44\%).

R. Whitlock, MD, PhD, FRCPC · A. Lamy, MD, MHSc, FRCPC Departments of Surgery (Cardiac Surgery) and Health Research Methods, Evidence, and Impact, McMaster University, Population Health Research Institute, Hamilton, ON, Canada

K. Um, BA · G. McClure, BSc

Michael G. DeGroote School of Medicine, Faculty of Health Sciences, McMaster University, Hamilton, ON, Canada

S. Connolly, MD, FRCPC

Department of Medicine (Cardiology), McMaster University, Population Health Research Institute, Hamilton, ON, Canada

S. Syed, MD, MSc, FRCPC

Department of Anesthesia and Critical Care, McMaster

University, Hamilton, ON, Canada 
Conclusions Benzodiazepine use is common among academic cardiac anesthesiologists in Canada. Nonetheless, heterogeneity exists between individual practices, suggesting clinical equipoise between restrictive and liberal administration of benzodiazepines for cardiac anesthesia. L'administration de benzodiazépines pendant la chirurgie cardiaque chez l'adulte: évaluation de la pratique actuelle des anesthésiologistes canadiens exerçant en milieu universitaire

\section{Résumé}

Contexte Les benzodiazépines sont fréquemment administrées pendant la chirurgie cardiaque en raison de leur effet limité sur l'hémodynamie et de leur rôle présumé dans la prévention de l'éveil peropératoire. Des inquiétudes sont récemment apparues concernant un risque accru de délirium lors de l'administration de benzodiazépines; par conséquent, une réduction de leur utilisation à l'unité des soins intensifs et dans la pratique périopératoire gériatrique a été observée. Nous disposons toutefois de très peu de données concernant l'usage actuel de benzodiazépines dans le contexte de la chirurgie cardiaque chez l'adulte.

Méthode Nous avons contacté tous les départements universitaires d'anesthésie au Canada afin d'identifier les anesthésiologistes cardiaques en pratique; ce groupe de praticiens a constitué notre cadre d'échantillonnage. Les renseignements concernant les données démographiques des patients, l'utilisation de benzodiazépines, leur type, leur posologie ainsi que les autres détails d'administration ont été obtenus par sondage électronique. Les réponses ont été analysées de façon descriptive.

Résultats Le sondage a été complété par 243/346 (70\%) des anesthésiologistes cardiaques. Onze pour cent des répondants n'administrent pas de benzodiazépines. Le midazolam était l'agent le plus fréquemment utilisé, avec une dose moyenne (écart type) de 4,9 (3,8) mg administrée à un patient moyen. Lorsqu'on a demandé aux répondants à quel pourcentage de leurs patients ils administraient des benzodiazépines, la réponse obtenue était bimodale. Les considérations les plus fréquentes influençant l'utilisation de benzodiazépines était l'âge du patient (73\%), son niveau d'anxiété (63\%), ses antécédents concernant l'utilisation d'alcool/drogues/benzodiazépines (60\%), et la présence de facteurs de risque d'éveil peropératoire (44\%).

Conclusion L'utilisation de benzodiazépines est fréquente parmi les anesthésiologistes cardiaques travaillant en milieu universitaire au Canada. Toutefois, les pratiques individuelles sont hétérogènes, ce qui laisse à penser qu'il existe un équilibre clinique entre l'administration restrictive vs libérale des benzodiazépines en anesthésie cardiaque.

Delirium is an acute disorder of cognition and attention that has been likened to "acute brain failure". ${ }^{1}$ It is recognized as the most common surgical complication in older adults, ${ }^{2,3}$ affecting up to $50 \%$ of older patients after an operation. ${ }^{1,4}$ Given its association with increased hospital length of stay, readmission, cognitive and functional decline, and mortality, ${ }^{5-8}$ delirium has significant consequences for both patients and communities. In the US alone, delirium in patients over the age of 65 is estimated to cost more than $\$ 164$ billion per year. ${ }^{9}$ Delirium may be preventable in $30-40 \%$ of cases, ${ }^{10,11}$ representing a target for intervention of substantial public health and political relevance.

Postoperative cardiac surgery patients are among those at greatest risk of delirium. ${ }^{1}$ Despite this, evidence regarding the prevention of delirium in this setting remains sparse. Among the modifiable precipitants of delirium identified, benzodiazepine use is a recurring association. Studies have found that both pre- ${ }^{12}$ and postoperative benzodiazepine $e^{2,13-16}$ use is associated with an increased risk of delirium, though the only randomized evidence comes from comparisons of benzodiazepine vs sedation with the alpha- 2 agonist dexmedetomidine in the post-cardiac surgery intensive care unit. ${ }^{14,16,17}$

Minimizing perioperative benzodiazepine use is an established approach to postoperative delirium prevention. This strategy is recommended by the American Geriatric Society ${ }^{3}$ and American College of Critical Care Medicine. ${ }^{18}$ Nonetheless, because of their favourable hemodynamic profile and amnestic properties, intraoperative benzodiazepines are routinely used in cardiac surgery. No studies have evaluated the effects of benzodiazepine-free anesthetic regimes on delirium after cardiac surgery. In addition, little is known about current practice among cardiac anesthesiologists in Canada, and there are no evidence-based practice guidelines that address the issue of intraoperative benzodiazepine administration. Anecdotally, anesthesiologists express extreme and dichotomous beliefs about whether benzodiazepines should be given to cardiac surgery patients. As such, we sought to describe current practice by undertaking a survey examining benzodiazepine administration during cardiac surgery. We hypothesized that among Canadian cardiac anesthesiologists there are substantial practice pattern variations in intraoperative benzodiazepine usage, supporting the need for a large 
clinical trial to establish the optimal approach to cardiac anesthesia care.

\section{Methods}

This study was designed and is reported according to the Strengthening the Reporting of Observational Studies in Epidemiology guidelines. ${ }^{19}$ Before commencing data collection, we obtained local Research Ethics Board approval on 8 February 2017, which waived the need for individual, informed consent. We developed a 16-item questionnaire (E-supplement 1) that assessed five domains: (1) practitioner characteristics, (2) the proportion of cardiac surgery patients receiving benzodiazepines, (3) the specific agents and corresponding doses that were typically given, (4) the determinants of benzodiazepine administration, and (5) individual beliefs about the role of benzodiazepines in preventing intraoperative awareness. We generated questionnaire items using an iterative process that included review of pertinent literature, informal dialogue with practitioners, and a focus group of cardiac anesthesiologists practicing at Hamilton General Hospital, which is affiliated with McMaster University. A group of cardiac anesthesia staff piloted the survey to ensure clarity; we sought to develop a questionnaire that balanced the amount of information collected with ease of completion.

The target population of the survey were licensed anesthesiologists who manage adult patients undergoing cardiac surgery in university-affiliated hospitals in Canada. We chose to exclude all trainees (fellows and residents). We also excluded anesthesiologists practicing in community hospitals because 1) they represent a minority of practitioners in Canada and 2) the lack of relationship with an academic institution made it difficult to confidently identify which community hospitals were providing cardiac surgery, which would have resulted in an uncertain denominator for our sampling frame. We used a stepwise process to develop our sampling frame. First, we contacted representatives from the departments of anesthesia of the thirteen universities in Canada with a medical school and obtained a contact person for each affiliated hospital providing cardiac surgery. Second, we contacted the individual identified to 1) ascertain the number of cardiac anesthesiologists at that site, 2) establish an agreement for their site to participate in the survey, and 3 ) develop a plan for survey distribution to eligible faculty. Identified cardiac anesthesiologists $(n=346)$ formed our sampling cohort.

We distributed a link to the survey to each departmental contact, who forwarded it to eligible faculty by email. The email also included information about the purpose of the study, a statement about the voluntary nature of participation, and information about participant anonymity. Study data were collected and managed using REDCap electronic data capture tools hosted at McMaster University. ${ }^{20}$ REDCap (Research Electronic Data Capture) is a secure, web-based application designed to support research data capture, including surveys. Recruitment and study materials were distributed in English and French. The survey was initially sent on 10 April 2017. A modified Dillman approach was employed. ${ }^{21}$ We sent three followup emails every 2 weeks and distributed non-binding incentives (coffee cards) to the 346 potential respondents to encourage survey completion. We closed the survey 1 June 2017.

Statistical analysis

Survey responses were analyzed descriptively using counts and percentages. Response rate was calculated by dividing the number of responses by the total number of cardiac anesthesiologists identified by site contacts $(n=346)$. Continuous variables were described using mean (standard deviation [SD]) or median [interquartile range (IQR)] depending on distributions. Statistical analyses were conducted using Stata version 12 (StataCorpLP, College Station, TX, USA).

\section{Results}

Of 346 cardiac anesthesiologists practicing at academic centres, $70 \%(243 / 346)$ responded to the survey. Table 1 reports respondent characteristics. The largest proportion (32\%) of respondents had been practicing anesthesia for more than 20 years. While most $(61 \%)$ had completed one year of fellowship, $25 \%$ (61/243) had no additional training in the subspecialty of cardiac anesthesia. The most common response, endorsed by $41 \%$ (99/243) of respondents, to the proportion of practice devoted to cardiac anesthesia was $21-40 \%$.

Table 2 reports the survey responses to questions about benzodiazepine administration to adult patients undergoing cardiac surgery. Eleven percent (26/243) of respondents do not administer benzodiazepines during cardiac surgery. Of those who reported using benzodiazepine(s), most (214/ $243 ; 88 \%$ ) anesthesiologists reported using midazolam, with a mean (SD) dose of 4.9 (3.8) $\mathrm{mg}$ given to an averagerisk, 65-yr-old patient undergoing coronary artery bypass graft on cardiopulmonary bypass (CPB). Other benzodiazepines reportedly used included lorazepam, diazepam, and oxazepam. When asked in what proportion of cardiac surgical patients they gave benzodiazepines, the response was bimodal (see Figure), with 23\% (54/243) either never giving them or giving them to less than $20 \%$ of 
Table 1 Respondent characteristics

\begin{tabular}{|c|c|}
\hline Variable & Summary statistic \\
\hline Years of practice: $(n, \%)$ & $\begin{array}{l}\leq 5 \text { years: } 25 / 243(10 \%) \\
>5-10 \text { years: } 44 / 243(18 \%) \\
>10-15 \text { years: } 52 / 243(21 \%) \\
>15-20 \text { years: } 41 / 243(17 \%) \\
>20 \text { years: } 78 / 243(32 \%) \\
\text { No response: } 3 / 243(1 \%)\end{array}$ \\
\hline Years practicing cardiac anesthesia: $(n, \%)$ & $\begin{array}{l}\leq 5 \text { years: } 35 / 243(14 \%) \\
>5-10 \text { years: } 44 / 243(18 \%) \\
>10-15 \text { years: } 56 / 243(23 \%) \\
>15-20 \text { years: } 44 / 243(18 \%) \\
>20 \text { years: } 62 / 243(26 \%) \\
\text { No response: } 2 / 243(0.8 \%)\end{array}$ \\
\hline Years of cardiac anesthesia fellowship training: $(n, \%)$ & $\begin{array}{l}\text { None: } 61 / 243(25 \%) \\
1 \text { year: } 147 / 243(61 \%) \\
2 \text { years: } 25 / 243(10 \%) \\
\geq 3 \text { years: } 7 / 243(3 \%) \\
\text { No response: } 3 / 243(1 \%)\end{array}$ \\
\hline Proportion of practice dedicated to cardiac anesthesia: (n, \%) & $\begin{array}{l}\leq 20 \%: 34 / 243(14 \%) \\
>20-40 \%: 99 / 243(41 \%) \\
>40-60 \%: 62 / 243(26 \%) \\
>60-80 \%: 23 / 243(10 \%) \\
>80-100 \%: 23 / 243(10 \%) \\
\text { No response: } 2 / 243(0.8 \%)\end{array}$ \\
\hline Province of practice (number surveyed): $(n, \%)$ & $\begin{array}{l}\text { BC (50): } 34 / 243(14 \%) \\
\text { AB (16): } 12 / 243(5 \%) \\
\text { SK (13): } 9 / 243(4 \%) \\
\text { MB (13): } 11 / 243(5 \%) \\
\text { ON (137): } 105 / 243(43 \%) \\
\text { QC (103): } 53 / 243(22 \%) \\
\text { NS (10): } 10 / 243(4 \%) \\
\text { NL (7): } 7 / 243(3 \%) \\
\text { No response: } 2 / 243(0.8 \%)\end{array}$ \\
\hline
\end{tabular}

$\mathrm{AB}=$ Alberta $\mathrm{BC}=$ British Columbia; $\mathrm{MB}=$ Manitoba $\mathrm{NL}=$ Newfoundland \& Labrador; NS = Nova Scotia; ON = Ontario; $\mathrm{QC}=\mathrm{Quebec} ; \mathrm{SK}$ $=$ Saskatchewan

patients and $51 \%(124 / 243)$ giving them to $80-100 \%$ of patients. When asked in what percentage of patients they believed it would be possible to provide cardiac anesthesia without using any benzodiazepine medication, 71\% (173/ 243 ) of respondents believed this would be possible in $>$ $80-100 \%$ of patients.

The most common considerations that influenced the benzodiazepine use or dose were patient age, anxious/ agitated patients, history of alcohol/drug/benzodiazepine use, and risk factors for intraoperative awareness. When asked which factors mandated the use of benzodiazepines during cardiac anesthesia, the majority (132/243; 54\%) responded that benzodiazepines were never mandated during cardiac anesthesia. Of those who believed that benzodiazepines were sometimes mandated during cardiac anesthesia, the factors identified, in decreasing order of frequency, included: history of awareness, history of alcohol or drug use, young age, preoperative benzodiazepine use, hemodynamic instability, and emergency surgery. 
Table 2 Responses to survey items

\begin{tabular}{|c|c|c|}
\hline Survey item & Responses & $n(\%)$ unless otherwise specified \\
\hline Number of respondents & - & $243 / 346(70 \%)$ \\
\hline \multirow{9}{*}{$\begin{array}{l}\text { Intraoperative benzodiazepine(s) used and } \\
\text { mean (SD) dose given to average risk, } \\
65 \text {-year-old patient undergoing cardiac } \\
\text { surgery on cardiopulmonary bypass } \\
\text { (CPB) }\end{array}$} & Midazolam & $214 / 243(88 \%)$ \\
\hline & Mean (SD) dose in $\mathrm{mg}$ & $4.9(3.8)$ \\
\hline & Lorazepam & $17 / 243(7 \%)$ \\
\hline & Mean (SD) dose in $\mathrm{mg}$ & $1.5(0.5)$ \\
\hline & Diazepam & $1 / 243(0.4 \%)$ \\
\hline & Mean (SD) dose in $\mathrm{mg}$ & $2.5(0)$ \\
\hline & Oxazepam & $1 / 243(0.4 \%)$ \\
\hline & Mean (SD) dose in $\mathrm{mg}$ & $15(0)$ \\
\hline & Benzodiazepines never used & $26 / 243(11 \%)$ \\
\hline \multirow{6}{*}{$\begin{array}{l}\text { Percentage of patients undergoing cardiac } \\
\text { surgery administered benzodiazepines }\end{array}$} & $0 \%$ & $26 / 243(11 \%)$ \\
\hline & $>0-20 \%$ & $28 / 243(12 \%)$ \\
\hline & $>20 \%-40 \%$ & $12 / 243(5 \%)$ \\
\hline & $>40 \%-60 \%$ & $13 / 243(5 \%)$ \\
\hline & $>60 \%-80 \%$ & $40 / 243(17 \%)$ \\
\hline & $>80 \%-100 \%$ & $124 / 243(51 \%)$ \\
\hline \multirow{5}{*}{$\begin{array}{l}\text { Percentage of cardiac surgery patients to } \\
\text { whom it is possible to provide cardiac } \\
\text { anesthesia without using } \\
\text { benzodiazepine medication }\end{array}$} & $>0-20 \%$ & $19 / 243(8 \%)$ \\
\hline & $>20 \%-40 \%$ & $13 / 243(5 \%)$ \\
\hline & $>40 \%-60 \%$ & $11 / 243(5 \%)$ \\
\hline & $>60 \%-80 \%$ & $27 / 243(11 \%)$ \\
\hline & $>80 \%-100 \%$ & $173 / 243(71 \%)$ \\
\hline \multirow{13}{*}{$\begin{array}{l}\text { Factor(s) influencing use or dose of } \\
\text { benzodiazepine }\end{array}$} & Patient body weight & $93 / 243(38 \%)$ \\
\hline & Patient age & $178 / 243(73 \%)$ \\
\hline & Published evidence & $30 / 243(12 \%)$ \\
\hline & Duration of CPB & $30 / 243(12 \%)$ \\
\hline & History of alcohol/drug/benzodiazepine use & $145 / 243(60 \%)$ \\
\hline & Anxious/agitated patients & $154 / 243(63 \%)$ \\
\hline & Risk factors for intraoperative awareness & $107 / 243(44 \%)$ \\
\hline & Procedure type & $41 / 243(17 \%)$ \\
\hline & Risk factors for postoperative delirium & $105 / 243(43 \%)$ \\
\hline & Presence/risk of hemodynamic impairment & $83 / 243(34 \%)$ \\
\hline & Need for awake intubation & $48 / 243(20 \%)$ \\
\hline & Benzodiazepines never used & $26 / 243(11 \%)$ \\
\hline & Other & $9 / 243(4 \%)$ \\
\hline \multirow{6}{*}{$\begin{array}{l}\text { Factor(s) that mandate use of } \\
\text { benzodiazepines during cardiac } \\
\text { anesthesia }\end{array}$} & Young age & $53 / 243(22 \%)$ \\
\hline & Emergency surgery & $23 / 243(10 \%)$ \\
\hline & History of awareness & $76 / 243(31 \%)$ \\
\hline & Hemodynamic instability & $33 / 243(14 \%)$ \\
\hline & History of alcohol or drug use & $55 / 243(23 \%)$ \\
\hline & Preoperative benzodiazepine use & $43 / 243(18 \%)$ \\
\hline
\end{tabular}


Table 2 continued

\begin{tabular}{|c|c|c|}
\hline Survey item & Responses & $n(\%)$ unless otherwise specified \\
\hline & Benzodiazepines are never mandated & $132 / 243(54 \%)$ \\
\hline & Other & $15 / 243(6 \%)$ \\
\hline \multirow{6}{*}{$\begin{array}{l}\text { Point(s) during a cardiac surgical } \\
\text { procedure when benzodiazepines } \\
\text { administered }\end{array}$} & Induction of anesthesia & $208 / 243(86 \%)$ \\
\hline & When starting $\mathrm{CPB}$ & $53 / 243(22 \%)$ \\
\hline & While on $\mathrm{CPB}$ as an infusion & $22 / 243(9 \%)$ \\
\hline & When coming off $\mathrm{CPB}$ & $28 / 243(12 \%)$ \\
\hline & Post-CPB & $14 / 243(6 \%)$ \\
\hline & Benzodiazepines never used & $26 / 243(11 \%)$ \\
\hline \multirow{2}{*}{$\begin{array}{l}\text { Estimated percentage of patients who } \\
\text { experience intraoperative awareness }\end{array}$} & Mean (SD) & $3.0(5.1)$ \\
\hline & Median (IQR) & $1(0-5)$ \\
\hline \multirow{3}{*}{$\begin{array}{l}\text { History of receiving complaints and/or } \\
\text { lawsuits from patient experience of } \\
\text { intraoperative awareness }\end{array}$} & Yes & $9 / 243(4 \%)$ \\
\hline & No & $231 / 243(95 \%)$ \\
\hline & Don't want to answer & $3 / 243(1 \%)$ \\
\hline \multirow{6}{*}{$\begin{array}{l}\text { Agreement with the statement 'I believe } \\
\text { that giving benzodiazepine medications } \\
\text { decreases the risk of intraoperative } \\
\text { awareness in cardiac surgery patients' }\end{array}$} & Completely agree & $39 / 243(16 \%)$ \\
\hline & Somewhat agree & $90 / 243(37 \%)$ \\
\hline & Neutral & $42 / 243(17 \%)$ \\
\hline & Somewhat disagree & $29 / 243(12 \%)$ \\
\hline & Completely disagree & $42 / 243(17 \%)$ \\
\hline & No response & $1 / 243(0.4 \%)$ \\
\hline
\end{tabular}

$\mathrm{BIS}=$ bispectral index; $\mathrm{CPB}=$ cardiopulmonary bypass; $\mathrm{EEG}=$ electroencephalograph; $\mathrm{IQR}=$ interquartile ratio; $\mathrm{SD}=$ standard deviation

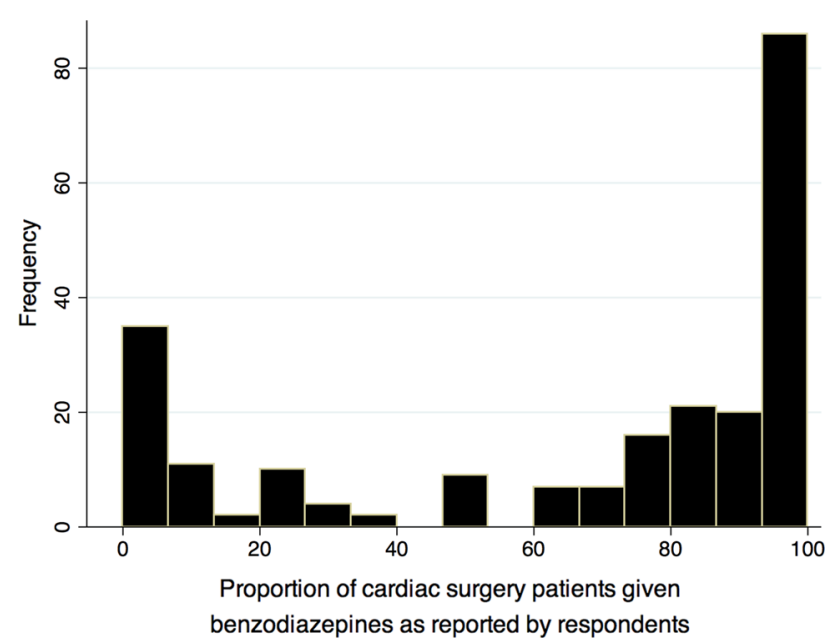

Figure Proportion of cardiac surgery patients to whom intraoperative benzodiazepines are administered as reported by 243 survey respondents

For respondents using benzodiazepines, the most common point during a cardiac surgical procedure when benzodiazepines were administered was induction of anesthesia, followed by the start of $\mathrm{CPB}$, when coming off CPB, while on CPB as an infusion, and at the end of the case or post-CPB.

Respondents estimated the proportion of their patients experiencing intraoperative awareness to be a median [IQR] estimate of 1 [0-5]\%. Nine (4\%) respondents identified having had complaints or lawsuits from cardiac surgery patients related to their experience of intraoperative awareness, 95\% did not, and 1\% did not want to answer this question. When asked whether they believed that benzodiazepines decrease the risk of intraoperative awareness in cardiac surgery patients, $16 \%$ of respondents were in complete agreement, $37 \%$ agreed somewhat, $17 \%$ were neutral, $12 \%$ somewhat disagreed, $17 \%$ completely disagreed, and $0.4 \%$ did not respond. 


\section{Discussion}

We surveyed Canadian academic cardiac anesthesiologists about their intraoperative use of benzodiazepines. Our results confirmed a dichotomous practice with respect to intraoperative benzodiazepine administration (see Figure); $11 \%(26 / 243)$ of respondents did not use benzodiazepines within their cardiac anesthesia practice. Most respondents believed that benzodiazepines are never mandated during cardiac surgery and that nearly all cardiac surgery patients could be provided an anesthetic without benzodiazepines.

The most common reasons-with the exception of patient anxiety or agitation-for using intraoperative benzodiazepines during cardiac surgery were directly or indirectly related to patient risk of intraoperative awareness or postoperative delirium. Indirect factors included patient age (which may be related to concerns about awareness in younger patients and delirium in older patients) and patient history of alcohol, drug, or benzodiazepine use (a risk factor for intraoperative awareness). ${ }^{22}$ Nonetheless, nonbenzodiazepine options-including opioids, anticholinergics, and alpha-2-agonists-exist for anxiolysis. Despite a recommendation from the American Society of Anesthesiologists that patients undergoing cardiac surgery should be given either a benzodiazepine or scopolamine to reduce the risk of intraoperative awareness, ${ }^{23}$ limited evidence supports the effectiveness of benzodiazepines in preventing awareness.

A systematic review examining the effectiveness of various anesthetic interventions to prevent intraoperative awareness found very low-quality evidence that benzodiazepines reduce awareness compared with thiopental, ketamine, and placebo. ${ }^{24}$ When examining the four included studies, the evidence of effect becomes questionable. The earliest study compared the effect of 2 $\mathrm{mg} \cdot \mathrm{kg}^{-1}$ of ketamine with $30 \mathrm{mg}$ diazepam and supplemental nitrous oxide on the incidence of awareness in 26 parturients undergoing forceps delivery: 4/13 patients experienced awareness with ketamine while none did with diazepam. ${ }^{25}$ This result may relate to the benzodiazepine, the use of nitrous oxide in the diazepam group, or the questionable equivalency of the two administered regimes. Haram et al. compared the incidence of 'unpleasant recall' after induction of general anesthesia using either thiopental or diazepam in 82 parturients. ${ }^{26}$ In the thiopental group, 5/ 40 patients had recall, while none did in the diazepam group. Nonetheless, the two regimes are unlikely to be equivalent; light anesthesia may explain the observed effect. Miller et al. evaluated the influence of adding graded doses of midazolam or placebo to a standard anesthetic induction on the incidence of intraoperative recall in 90 patients undergoing arthroscopic knee surgery. ${ }^{27}$ This trial was stopped early after $4 / 21$ patients in the placebo group and 2/69 patients in the midazolam group experienced intraoperative awareness. Chance or lighter anesthesia may explain this finding.

Studies have found an association between delirium and both preoperative ${ }^{12}$ and postoperative benzodiazepine $e^{2,13-16}$ use. In a nested case-control study, the odds of delirium were 3.0 (95\% confidence interval [CI], 1.3 to 6.8 ) higher in non-cardiac surgery patients who were administered benzodiazepines post-operatively. ${ }^{2}$ In prospective observational data, for every $\mathrm{mg}$ of midazolam administered after cardiac surgery, patients were 7-8\% more likely to develop delirium, suggesting a dose-response effect. ${ }^{15}$ The development of delirium is hypothesized to relate to imbalances in the release, synthesis, and degradation of gamma-aminobutyric acid (GABA) and other neurotransmitters. ${ }^{28}$ Because of their affinity for GABAergic receptors in the brain regions responsible for consciousness, benzodiazepine-induced decreases in arousal may cause unpredictable neurotransmission and delirium. ${ }^{28}$

Randomized controlled trials have compared benzodiazepines with dexmedetomidine for sedation in the post-cardiac surgery intensive care unit. ${ }^{14,16,17}$ In a mixed medical and surgical ICU population, sedation with dexmedetomidine resulted in more days alive without delirium (median days 7 vs $3 ; P=0.01$ ) than lorazepam. ${ }^{14}$ In another trial, 54\% of patients treated with dexmedetomidine developed delirium compared with $77 \%$ of patients treated with midazolam (absolute risk increase $=23 \% ; 95 \% \mathrm{CI}, 14 \%$ to $33 \% ; P=0.001) .{ }^{16}$ This evidence has led to recommendations to minimize benzodiazepine use in elderly and ICU patients. ${ }^{3,18}$ Benzodiazepine administration in the ICUs in Canada is no longer considered consistent with standard of care. ${ }^{18,29}$ Nonetheless, our survey suggests that intraoperative benzodiazepine use remains common in cardiac surgery, possibly because of the absence of randomized evidence showing harm.

Current heterogeneity in practice reflects a gap in the literature and the concerns about the relationship of benzodiazepines with postoperative delirium and beliefs about their role in preventing intraoperative awareness. Our respondents endorsed giving benzodiazepines to approximately half of patients within their cardiac anesthesia practices, but believed that it was possible to give nearly all patients a cardiac anesthetic without benzodiazepines. The use of both minimized and liberal approaches to benzodiazepines by anesthesiologists during cardiac surgery confirms the existence of equipoise. This heterogeneous practice emphasizes the need for a trial to establish best practice.

Our study has several limitations. First, we surveyed Canadian academic cardiac anesthesiologists; their practice may not reflect that of all practitioners. Nonetheless, this 
group represents the majority of practitioners and we felt that this sampling frame would allow us to evaluate whether the dichotomous beliefs about benzodiazepine use we had anecdotally observed were reflected in practice. Second, we did not ask about what medications our respondents used as alternatives to benzodiazepines. Finally, though our response rate was excellent, 30\% (103/346) of academic cardiac anesthesiologists in Canada did not participate; their practice may differ.

Despite these limitations, our survey provides important information about Canadian cardiac anesthesia practice. The substantial variation in the usage of benzodiazepine during cardiac surgery highlights the existing community equipoise and suggests competing concerns about the role of benzodiazepines in preventing intraoperative awareness and their relationship with postoperative delirium. Given the lack of data supporting either approach, further study is needed to address this evidence gap. To address this gap, we are currently conducting a two-site pilot study (clinicaltrials.gov identifier NCT03053869), whose objective is to show the feasibility of conducting a multicentre, randomized cluster crossover trial evaluating the impact of benzodiazepine-free cardiac anesthesia on the incidence of postoperative delirium among adult cardiac surgery patients.

\section{Financial disclosure and conflict of interest None declared.}

Editorial responsibility This submission was handled by Dr. Philip M. Jones, Associate Editor, Canadian Journal of Anesthesia.

Author contributions Jessica Spence contributed substantially to all aspects of this manuscript, including conception and design; acquisition, analysis, and interpretation of data, and drafting the manuscript. Emilie Belley-Côté, PJ Devereaux, and Stuart Connolly contributed substantially to the conception and design of the study, interpretation of data, and drafting of the manuscript. Richard Whitlock, André Lamy, and Yannick LeManach contributed substantially to the conception and design of the study, and drafting of the manuscript. Kevin Um and Graham McClure contributed substantially to the acquisition of data. Summer Syed oversaw the conception and design of the study, and drafting of the manuscript.

\section{References}

1. Inouye SK, Westendorp RG, Saczynski JS. Delirium in elderly people. Lancet 2014; 383: 911-22.

2. Marcantonio ER, Juarez G, Goldman L, et al. The relationship of postoperative delirium with psychoactive medications. JAMA 1994; 272: 1518-22.

3. American Geriatrics Society Expert Panel on Postoperative Delirium in Older Adults. Postoperative delirium in older adults: best practice statement from the American Geriatrics Society. J Am Coll Surg 2015; 220(136-48): e1.

4. Dasgupta M, Dumbrell AC. Preoperative risk assessment for delirium after noncardiac surgery: a systematic review. J Am Geriatr Soc 2006; 54: 1578-89.
5. Newman MF, Kirchner JL, Phillips-Bute B, et al. Longitudinal assessment of neurocognitive function after coronary-artery bypass surgery. N Engl J Med 2001; 344: 395-402.

6. Koster $S$, Hensens $A G$, van der Palen J. The long-term cognitive and functional outcomes of postoperative delirium after cardiac surgery. Ann Thorac Surg 2009; 87: 1469-74.

7. Koster S, Hensens AG, Schuurmans MJ, van der Palen J. Consequences of delirium after cardiac operations. Ann Thorac Surg 2012; 93: 705-11.

8. Stransky M, Schmidt C, Ganslmeier P, et al. Hypoactive delirium after cardiac surgery as an independent risk factor for prolonged mechanical ventilation. J Cardiothorac Vasc Anesth 2011; 25: 968-74.

9. Leslie DL, Marcantonio ER, Zhang Y, Leo-Summers L, Inouye $S K$. One-year health care costs associated with delirium in the elderly population. Arch Intern Med 2008; 168: 27-32.

10. Inouye SK, Bogardus ST Jr, Charpentier PA, et al. A multicomponent intervention to prevent delirium in hospitalized older patients. N Engl J Med 1999; 340: 669-76.

11. Marcantonio ER, Flacker JM, Wright RJ, Resnick NM. Reducing delirium after hip fracture: a randomized trial. J Am Geriatr Soc 2001; 49: 516-22.

12. Redelmeier DA, Thiruchelvam D, Daneman N. Delirium after elective surgery among elderly patients taking statins. CMAJ 2008; 179: 645-52.

13. Pandharipande P, Shintani A, Peterson J, et al. Lorazepam is an independent risk factor for transitioning to delirium in intensive care unit patients. Anesthesiology 2006; 104: 21-6.

14. Pandharipande PP, Pun BT, Herr DL, et al. Effect of sedation with dexmedetomidine vs lorazepam on acute brain dysfunction in mechanically ventilated patients: the MENDS randomized controlled trial. JAMA 2007; 298: 2644-53.

15. Taipale $P G$, Ratner $P A$, Galdas $P M$, et al. The association between nurse-administered midazolam following cardiac surgery and incident delirium: an observational study. Int $\mathbf{J}$ Nurs Stud 2012; 49: 1064-73.

16. Riker RR, Shehabi Y, Bokesch PM, et al. Dexmedetomidine vs midazolam for sedation of critically ill patients: a randomized trial. JAMA 2009; 301: 489-99.

17. Maldonado JR, Wysong A, van der Starre PJ, Block T, Miller C, Reitz BA. Dexmedetomidine and the reduction of postoperative delirium after cardiac surgery. Psychosomatics 2009; 50: 206-17.

18. Barr J, Fraser GL, Puntillo K, et al. Clinical practice guidelines for the management of pain, agitation, and delirium in adult patients in the intensive care unit. Crit Care Med 2013; 41: 263-306.

19. von Elm E, Altman DG, Egger M, et al. The Strengthening the Reporting of Observational Studies in Epidemiology (STROBE) statement: guidelines for reporting observational studies. Lancet 2007; 370: 1453-7.

20. Harris PA, Taylor R, Thielke R, Payne J, Gonzalez N, Conde JG. Research electronic data capture (REDCap)-a metadata-driven methodology and workflow process for providing translational research informatics support. J Biomed Inform 2009; 42: 377-81.

21. Dillman DA, Smyth JD, Christian LM. Internet, Mail, and MixedMode Surveys : The Tailored Design Method. 3rd ed. NJ: John Wiley \& Sons; 2009 .

22. Orser BA, Mazer CD, Baker AJ. Awareness during anesthesia. CMAJ 2008; 178: 185-8.

23. American Society of Anesthesiologists Task Force on Intraoperative Awareness. Practice advisory for intraoperative awareness and brain function monitoring: a report by the American Society of Anesthesiologists Task Force on Intraoperative Awareness. Anesthesiology 2006; 104: 847-64.

24. Messina AG, Wang M, Ward MJ, et al. Anaesthetic interventions for prevention of awareness during surgery. Cochrane Database Syst Rev 2016; 10: CD007272. 
25. Ellingson A, Haram $K$, Sagen $N$. Ketamine and diazepam as anaesthesia for forceps delivery. A comparative study. Acta Anaesthesiol Scand 1977; 21: 37-40.

26. Haram K, Lund T, Sagen N, Boe OE. Comparison of thiopentone and diazepam as induction agents of anaesthesia for caesarean section. Acta Anaesthesiol Scand 1981; 25: 470-6.
27. Miller DR, Blew PG, Martineau RJ, Hull KA. Midazolam and awareness with recall during total intravenous anaesthesia. Can J Anaesth 1996; 43: 946-53.

28. Gunther ML, Morandi A, Ely EW. Pathophysiology of delirium in the intensive care unit. Crit Care Clin 2008; 24: 45-65.

29. Ferrell BA, Girard TD. Sedative choice: a critical decision. Am J Respir Crit Care Med 2014; 189: 1295-7. 